\title{
Bringing the universe to the street. A preliminary look at informal learning implications for a large-scale non- traditional science outreach project
}

\author{
Kimberly Arcand and Megan Watzke
}

\begin{abstract}
From Earth to the Universe" (FETTU) is a collection of astronomical images that showcase some of the most popular, current views of our Universe. The images, representing the wide variety of astronomical objects known to exist, have so far been exhibited in about 500 locations throughout the world as part of the International Year of Astronomy. In the United States, over 40 FETTU exhibits have occurred in 25 states in such locations as libraries, airports, nature centers, parks and college campuses. Based on preliminary evaluations currently underway, this project - a large-scale, worldwide astronomy outreach in non-traditional locations - has unique opportunities and implications for informal science learning. We present some early findings from the observational section of the exhibit's formal evaluation in five selected locations in the U.S. and U.K., including emphasis on inter-organizational networking, visitor attention and participant make-up as well as generative aspects of the exhibit.
\end{abstract}

\section{Context}

The "From Earth to the Universe" (FETTU) project is a worldwide effort to bring astronomical images and their science to the public in non-traditional locations such as public parks, metro stations, shopping malls, hospitals, libraries, and even prisons (see figure 1). By showcasing current astronomy images as "vibrant shapers of knowledge," FETTU strives to promote widespread access to current scientific knowledge and astronomical imagery, and increase scientific awareness. ${ }^{1,3}$ FETTU is a major project for the International Year of Astronomy 2009 (IYA2009), a global effort initiated by the International Astronomical Union (IAU) and the United Nations Educational, Scientific and Cultural Organization (UNESCO) to celebrate the $400^{\text {th }}$ anniversary of Galileo's telescope. Over 65 countries with about 500 exhibitions are participating in FETTU. From tiny villages to the largest cities - with budgets large and small - FETTU has been featured on every continent except Antarctica. ${ }^{2}$

\section{Objective}

FETTU has the ability to play a role in increasing the public's scientific awareness and promoting widespread access to current scientific knowledge by utilizing voluntary participation in viewing image exhibitions in unexpected yet public spaces. In short, it is intended to help democratize access to the science behind these astronomical images. It also provides an opportunity to pose and research useful questions in regard to informal science education. For example, what are the effects on informal learning of a large-scale non-traditional science outreach project - both in the U.S. and also in other countries? Can aesthetically-pleasing images serve as a bridge between the public and some of the complex concepts inherent in astrophysics? 


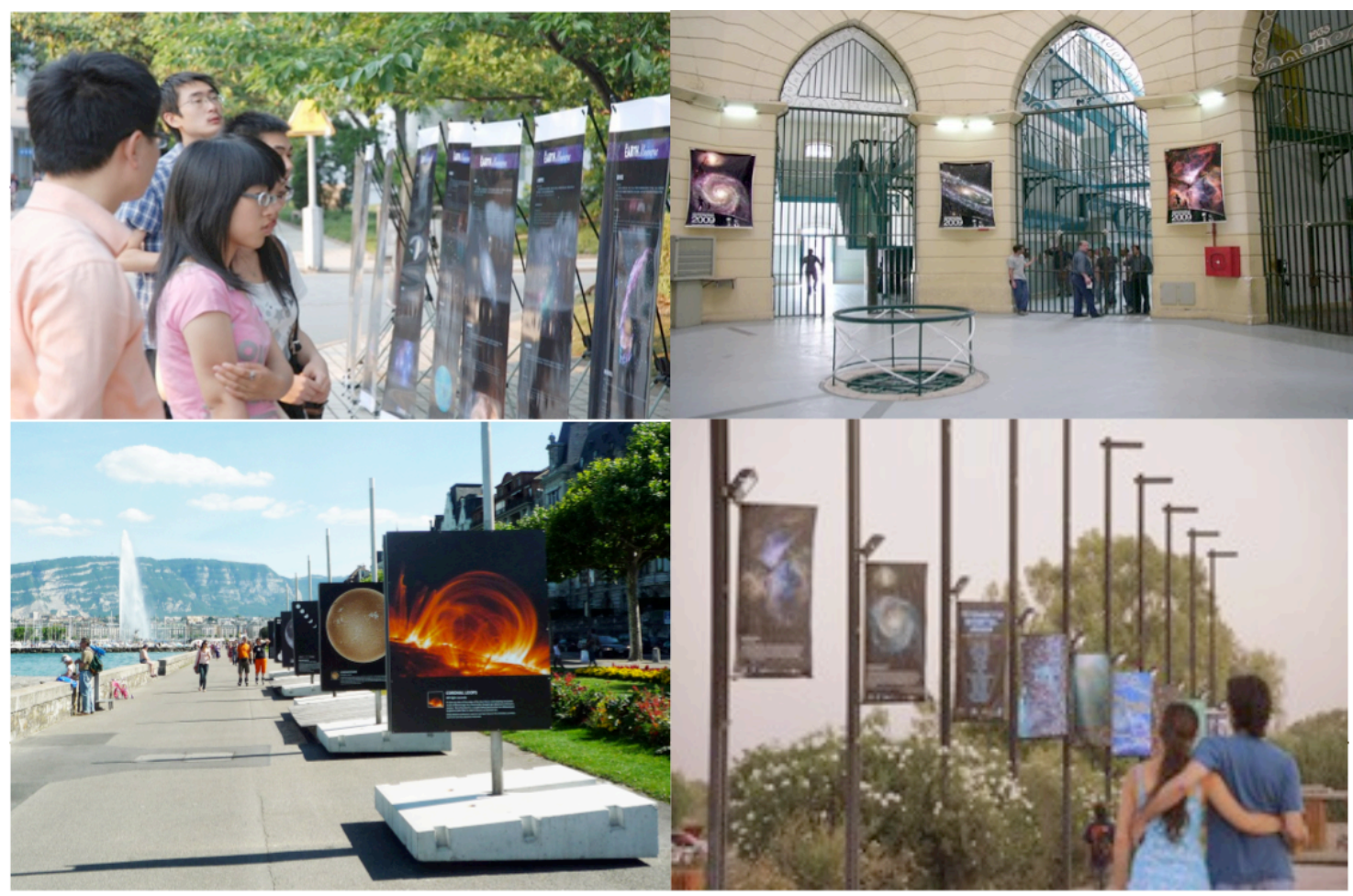

Figure 1. FETTU on display on a college campus in Shanghai, China (upper left), in a prison in Coimbra, Portugal (upper right), along the lake in Geneva, Switzerland (lower left), and in a park in Mendoza, Argentina (lower right).

The objective of the FETTU exhibits is to provide an introduction to modern astronomical information with a pipeline to deeper learning once a connection is established through the aesthetics of the displays. This is encouraged through on-site activities implemented by the local people preparing the exhibits ("local organizers") such as interactions with scientists and educators through question-and-answer sessions, telescope viewings or visitor "tours"; scavenger hunts for family learning, creative thinking and play; informational handouts such as exhibit guides, postcards, posters and other handouts; referrals to online and regional educational resources, and more.

This article will address the preliminary observational data collected at FETTU sites visited by the first author as well as venues where the authors have received standardized observation notes and interviews directly from the local organizers. Therefore, this paper will focus mainly on the U.S.-based efforts in the FETTU project, and will outline some wide-reaching questions that could be investigated with FETTU and projects like it.

Other articles that address the outcomes of international FETTU efforts will be forthcoming.

\section{Methods: establishing the FETTU project}

The beginning steps for FETTU included compiling a selection of 125 astronomy images that had been chosen by a committee of astronomers and outreach specialists to showcase a broad view of current astronomical science and imagery. The images (of real data only - artist's illustrations were excluded) represent a wide variety of cosmic objects that are known to exist: planets, comets, stars, nebulae, galaxies and galaxy clusters. All types of light were included, from the long wavelengths of radio and infrared to the shorter wavelengths of ultraviolet and X-ray light. Textual descriptions including object, color, scale, and observatory information were proofed for accuracy and, along with the images, were curated into a package that was free to download and use for outreach events during IYA2009 and continuing for events into 2010 . 
The materials were translated into almost 40 languages including French, German, Gujarati, Hmong, Italian, Japanese, Mandarin, Portuguese, Spanish, Turkish, and made available to event organizers through the FETTU web site and newsletters. In the U.S., a NASA grant funded versions of the exhibit which contained information in both English and Spanish on the image panels.

An important administrative or structural characteristic of the FETTU project was flexibility. No restrictions were imposed on how the images were to be physically exhibited as long as they were displayed in the spirit of IYA2009. ${ }^{3}$ Local organizers were encouraged to use whatever monetary resources, venue options, cultural preferences, etc., to create a FETTU exhibit that worked for their area, leveraging their knowledge to best portray the science display as an accessible, social, and livable experience for their audience. ${ }^{4}$

To deepen the possible path to learning, online and printable tutorials covering the electromagnetic spectrum, astronomical object types, "false" (or representative) color, cosmic scale and distance were provided, in addition to a telescope/image guide and other educational activities. Local organizers used the materials to create their own culturally-appropriate FETTU handouts to accompany their exhlibits, including booklets in Bulgaria, calendars in France, badges in Canada, postcards in Italy, and trading cards in South America.

\section{Methods: evaluation strategy}

The evaluation strategy employed in the U.S. for the NASA-funded FETTU locations is based on informal education evaluation models recommended by the National Science Foundation (NSF) publication, "Framework for Evaluating Impacts of Informal Science Education Projects" (2008). Consultation from an expert at the Smithsonian Astrophysical Observatory allowed for a preliminary evaluation of the Liverpool, U.K. prototype (discussed further under "Case Studies" below) using exhibition observation and exit-interview protocols that were adapted for FETTU data collection. These protocols were posted to the FETTU web site and circulated in newsletters to organizers worldwide.

Some countries - such as the U.S., Brazil, and the U.K. - had the budget and time to commit to performing full evaluations with similar methodology as described in the next paragraph. Others, including Argentina, Iceland, India, and Uruguay, were able to perform basic data collection of audience size and makeup, duration of exhibit, number of image panels, etc. The FETTU co-chairs have also collected interview data (paths of FETTU exhibit creation, management of project, key points of exhibit success, effect of experience with FETTU on future outreach plans, etc.) with approximately 25 of the international FETTU organizers and intend to collect more in 2010.

In the U.S., FETTU site evaluations are collecting information about the use of non-traditional settings and space science imagery to attract new audiences to further engagement with astronomy learning opportunities. The strategy has been to evaluate the impact of FETTU on three audiences using a master evaluation protocol that was adapted for local venues and different exhibit sizes. The audiences targeted were:

1. Viewing audiences (exploring knowledge, awareness, understanding of science content, enjoyment, inspiration, and behavior).

2. Staff of host-partner institutions (building up the capacity to organize outreach events, increasing knowledge of programs)

3. Local community partners at each site (nurturing new partnerships for science education for sustainability)

Each viewing audience was surveyed at the exhibit site (see Appendixes 1a-1b for questions). This samples the immediate impact and required 1-2 data collectors for 2-3 days per site. At least 15 separate U.S. locations have conducted the evaluations with larger sites collecting 50-100 data points each. 


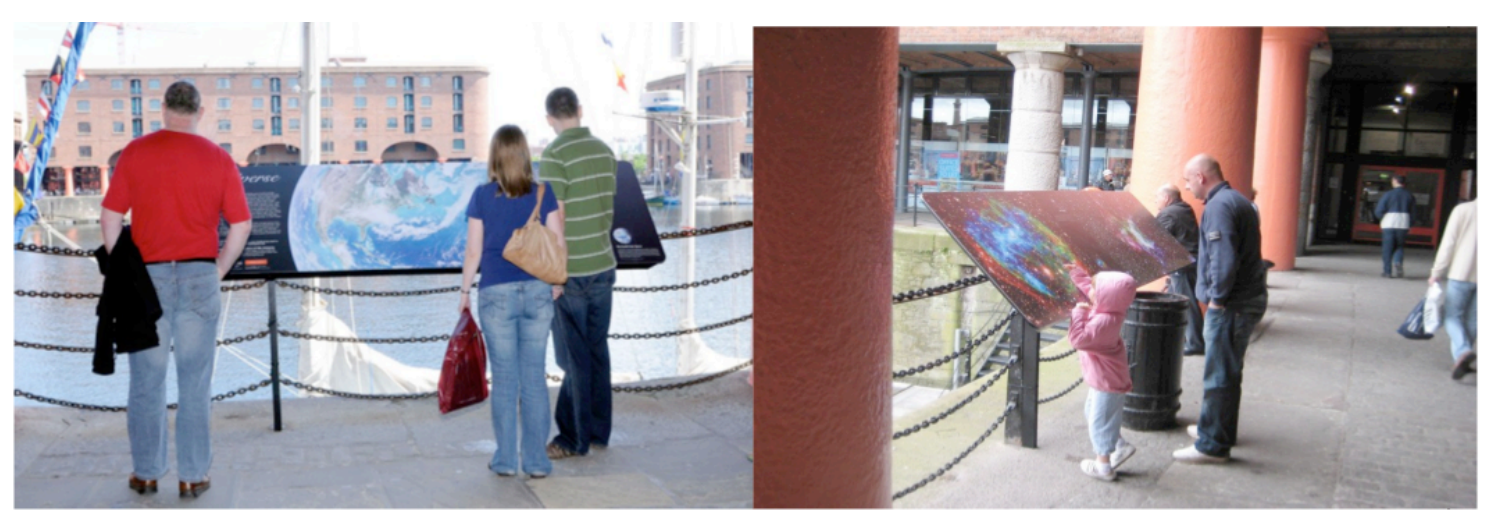

Figure 2. June 2008 - Liverpool, UK "From Earth to the Universe" at Albert Docks. Photo credits: K.K.Arcand.

\section{Results: case studies}

"From Earth to the Universe" has brought astronomical images and their contextual information to millions of people around the globe during IYA2009. Many FETTU exhibits have been placed in locations where science content is likely unexpected by the public. Examples of such locations include the hallways of the Iranian Parliament, outside the plaza of Reykjavik, Iceland, in an art museum in Shanghai, China, during a space art contest for children in Enayetpura, Bangladesh, throughout many villages in Uruguay, and at Unesco World Heritage sites such as Stonehenge in the U.K.

Research conducted in museum studies provides information on how individuals view objects similar to astronomical images, such as works of art and historical artifacts. ${ }^{5}$ An important issue is that museum visitation is voluntary in nature. ${ }^{6}$ Visitors are there because they want to be, stopping at displays that interest them and staying as long as their interest is maintained. ${ }^{7}$ In all settings, the desire to educate must be mediated with the interest levels and background of the visitors. ${ }^{8,9}$ To our knowledge, there has never been a rigorous scholarly study to evaluate how such voluntary, self-directed behavior is affected when the content is astronomical imagery. Therefore, the FETTU project provides an opportunity to study how the public interacts with science in the unique settings in which FETTU has appeared.

The next several sections of this article will present a sampling of case studies of FETTU exhibits in the U.S. and U.K.

\section{Liverpool, UK: the prototype}

The first FETTU exhibition occurred in Liverpool, U.K. at Albert Docks in June 2008 (figure 2). This location was selected because of an early partnership with the Science Photo Library, a U.K.-based company that provided much support for the prototype effort. Albert Docks is a well-visited section of Liverpool (tourism surveys suggest that $64 \%$ of visitors to the area stop at Albert Docks) with a bustling atmosphere of shoppers, tourists, walkers and Tate Liverpool attendants. Two days of multiple hour-long observation sessions of exhibit participants showed that approximately half of the people walking along the dock stopped to look at the pictures and about 1 in 6 of all strollers viewed the accompanying textual materials.

The duration of visits ranged from brief looks (2-3 seconds per image visited) to more lengthy stays (2-3 minutes per image visited) with an estimated average at 30 seconds. Longer visits occurred in a higher percentage with groups of visitors versus individuals. The exceptions to this "group visitation" rule occurred with the images located where waiting frequently occurred for other purposes (e.g., outside the restrooms and near the café). These "waiting room" images typically had the longest duration of visits by individuals (up to 4 minutes). In general, the voluntary time spent looking at the images, and the time to read the captions was found to be similar to what is found in studies of individuals looking at art in a museum. ${ }^{10}$

The observations noted that children often questioned and discussed the images with their intergenerational families, and couples pointed out features to note with each other - demonstrating the importance of learning as participation in a social world. ${ }^{11}$ Parents here seemed to function as the "expert," reading the narrative text and answering the additional questions of the "novice" or child. 
Interestingly, children frequently approached the panels with their hands closely following their eyes, while adults would often stand with hands in their pockets (figure 2).

The preliminary data from Liverpool also suggests that the brightest and visually "loud" images attract the most attention. The use of color in astronomy images in general appears to enhance their appeal. The interview questions for participants did not pointedly ask about color appeal and color comprehension issues, but a follow-up study on this topic would be useful.

\section{Across the U.S.: implementation during IYA2009}

In the United States, NASA funded FETTU exhibits in the Chicago and Atlanta international airports, and a 50-image traveling version that visited several of the country's largest cities (see figure 3 ). The stops for this "traveling FETTU" included an airport, street fair, libraries, universities, and science museum campuses. In the examples below, a sample of these different venues and various aspects of their location types are given.

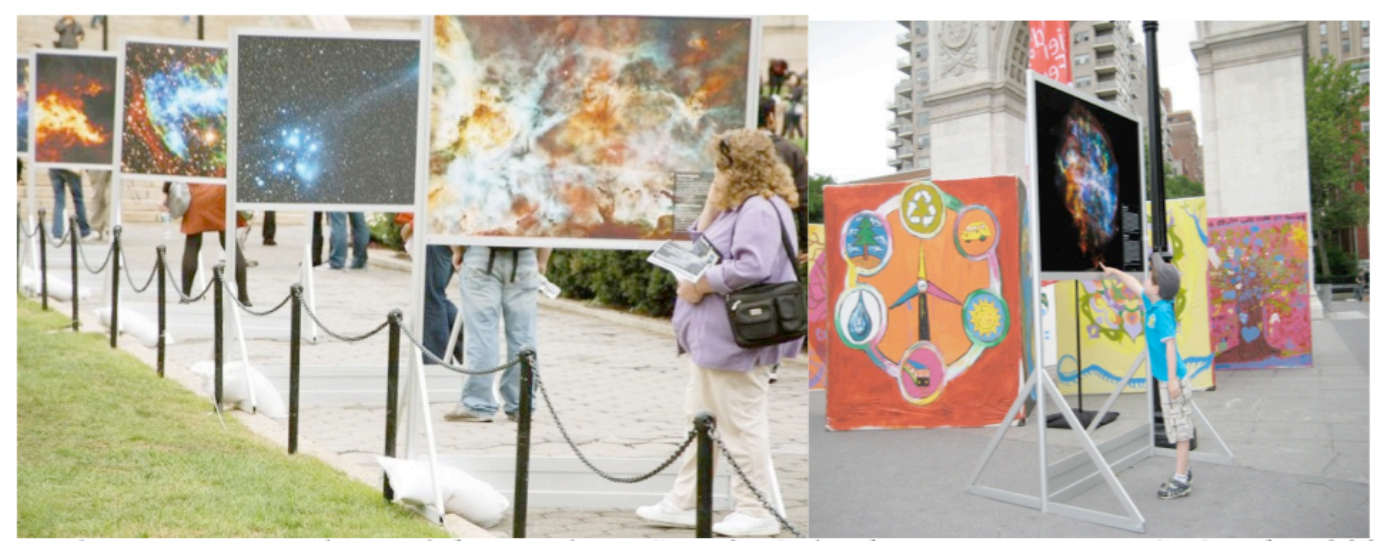

Figure 3. FETTU Traveling exhibits in the U.S. Left: Columbia University, NYC, October 2009. Right: World Science Festival in Washington Square Park, NYC, June 2009. Photo credits: K.K.Arcand.

\section{New York City: the rhetoric of play}

The World Science Festival (WSF) hosted FETTU as part of their Family Day in Washington Square Park on June 14, 2009. The images were arranged in a circle around the fountain affecting a promenade for event participants and incidental attendees (e.g., dog-walkers and park visitors). The street fair included hands-on activities, expert discussions, and robotics demonstrations occurring around, near and in front of FETTU. The social nature of the event with games, competitions, and audio stimulation, contributed to a lively atmosphere for people of all ages, and helped to engage the participants to constructively "play along". In addition, presenting astronomy and science in an open-air location - at a large urban park - utilized the evidence that activities executed out-of-doors help foster socialized aspects of learning in a way less stressful to participants. ${ }^{4}$

Event organizers estimated WSF visitor totals well into the tens of thousands (for reference, the 2008 festival attendance was 100,000 according to the New York Police Department). Conservative estimates note that approximately $1 / 4$ of the event attendees visited FETTU. Observations noted a similar pattern to Liverpool's for viewing duration and social arrangement (participants as individuals versus groups, children with families versus couples). Family participation in informal science learning environments provides opportunities for members of the family to explore and reflect on the material presented while on-site and - maybe more importantly - later at their own pace in other locations (in the car, during dinner, at home, etc.). ${ }^{4}$ The situation of these physical images in unexpected places utilizes the research that simplifying and socializing abstractions of the science by presenting the concepts in a more comprehensible, attractive and playful way attracts the voluntary participation of the viewer. ${ }^{1}$ 


\begin{abstract}
"A recurring theme is that the images make it easy for people to stretch their imagination and put words to questions that they've either wondered about before but had trouble articulating or never realized that they could wonder about before coming across a particular image... Another constant is witnessing children teaching their parents as well as parents sharing knowledge with their children."

- Laura Trouille, graduate student in physics/astronomy \& FETTU organizer
\end{abstract}

\title{
Tucson, AZ: exposure for visitors and workers alike
}

The traveling FETTU exhibit was hosted at Tucson International Airport (TIA) in Arizona from February 20 through March 25, 2009 in the upper ticketing area. The event was supported by a national press release, which was relayed to local media; both daily newspapers in Tucson mentioned FETTU in articles, including page 1 in the Tucson Citizen (circulation estimated at 25,000). An estimated 4.5 million travelers pass through TIA per year, according to the director of public affairs for the airport. Given that March is an extra-busy month of tourist events as well as a popular spring break travel period, the airport staff estimated that more than $1 / 12^{\text {th }}$ of this total $(>400,000$ people) passed through the airport during the period FETTU was there.

Evaluation data collection for the Tucson exhibit (20 data points) was completed by Doug Isbell, an astronomy outreach professional. He noted a large fraction of airport visitors rushed by the images without obvious acknowledgement of the exhibit. However, of the $1 / 5^{\text {th }}$ of the total traffic he observed that stopped to participate in FETTU during 15-minute windows, about 80-90\% of them engaged with the display (to read or note items of interest vs. just glance). Because of the high volume of traffic the airport receives, a significant quantity of visitors was still reached by FETTU despite the low percentage. One suggestion to improve the ratio of visitors who participated in FETTU was to select a location where guests would need to wait (e.g., flight arrivals/baggage claim), thus perhaps fostering a "slower" atmosphere for attempting more effective science outreach.

The host site itself (the airport authority) had positive feedback, noting that the airport staff was particularly sorry to see it go:

\begin{abstract}
"This has been a VERY popular exhibit. I wish we could have kept it a lot longer. My observations $\ldots$ and the ones of my co-workers... are very different. I watch travelers... bags in tow, walk from panel to panel staring at the images and reading every word. I've even seen people taking photographs of each panel. I can't tell you how much we're going to miss the exhibit. As I was removing it this afternoon, at least a dozen co-workers begged me to keep it up."

-Viki Matthews, TIA Airport Spokesperson
\end{abstract}

It is here that an important aspect of the project became apparent. Not only are exhibit visitors being affected in various ways by the displays of astronomy images in non-traditional locations, but also the local organizers and the people included in those environments in which the organizers work. For example, in Tucson and Atlanta, an airport now has a relationship with their local astronomical community - a collaboration not in existence previous to FETTU. The Atlanta airport-astronomy connection lead to a subsequent call and selection of art for a special local artists' exhibition through the Airport Art Program, and opened in the airport's Atrium Gallery on June 12, 2009.

Such networks - with the capacity to organize outreach events, increase knowledge of astronomy, and increase opportunities to link science and the arts - have sprung up at multiple FETTU sites. In the Bay Area around San Francisco, California, a new consortium of astronomy outreach professionals, universities, museums, and other organizations was created to host FETTU throughout the region. Twenty-six different exhibit locations were produced from March-December 2009, funded by NASA's Lunar Science Institute, the Fermi and Swift missions through Sonoma State University, and several others. This consortium hopes to continue beyond IYA2009 and is actively looking for new means to leverage their partnership to raise scientific awareness. For instance, they have recently worked together to plan an event in 2010 that will utilize Braille astronomy panels for display at the Tech Museum from in May 2010. 


\title{
Memphis, TN: a trip to the library
}

The city of Memphis, Tennessee hosted FETTU from April 1-30, 2009. The exhibit was held in the gallery of the Benjamin Lee Hooks Central Library with heavy community support. Rhodes College provided an opening event on April 1, 2009, attracting approximately 300 visitors to astronomy lectures (with dissemination of handouts). The most circulated local newspaper, the Commercial Appeal, published an article on April 2, promoting the educational value of the exhibit.

One key was a group of volunteers from the Memphis Astronomical Society (MAS) who, in addition to completing the assembly of FETTU, staffed the exhibit and helped with evaluation efforts. By sharing their knowledge, the amateur astronomers were able to raise the level of engagement for visitors -including those from local high schools. Approximately 140 visitor evaluations and 20 observations were collected. The feedback was positive and specific comments indicated small learning gains or levels of inspiration such as: "I learned the world is infinite. We are trying to make sense of this infinite beauty." and "Totally enjoyed it. [This is] not taught enough in school. Need more exposure for children." (see Appendix 2 for additional comments).

\section{Columbia University, NYC: a case of cosmic consciousness}

On October 4, 2009, the traveling FETTU exhibit was launched outdoors at Columbia University in New York City in front of the library for two weeks. The astronomy department staffed a table from 9am-7pm each day while the exhibit ran to hand out materials, and answer visitor questions. The organizers hosted a "Stump the Astronomer" event and had telescopes for public viewing. The table was busy with an estimated $2 / 3^{\text {rd }}$ of exhibit guests stopping by, allowing participants to model inquiry behavior that supports science learning in informal environments. ${ }^{4}$ Using a counter the organizers tallied 7,000 attendants during the first eight days of the exhibit while it was staffed (as it was outdoors, additional visitors could have occurred "off-hours").

The exhibit, with the additional materials, activities and interactions with experts provided an opportunity for high levels of engagement. Interviews conducted with 50 visitors recorded positive feedback and specifics on what they learned. Observations also noted parallels with the Liverpool and WSF events in participant behavior. One visitor embedded the experience in such a way that she wrote a generative article for her university newspaper. She connected the cosmic images with the "cosmic consciousness" of her philosophy studies, stretching across disciplines to interpret the material.

\begin{abstract}
“'The starry heaven above me and the moral law within me' filled Immanuel Kant's mind 'with ever new and increasing wonder and awe.' He continued, 'I see them in front of me and unite them immediately with the consciousness of my own existence.' As I gazed at the photographs of planets, galaxies, nebulae, and clusters in the exhibition "From Earth to the Universe" last week, I contemplated what Kant said and wondered whether we forget too often our place, as tiny human beings, in this vast universe...In the end, we are left with 50 images of outer space that we can't ignore on our way to educating ourselves for a better future. And I almost wish that these photographs were artistic fabrications, so that I can just say, "How pretty," and keep walking. -Yurina Ko, Columbia Spectator, 18 October 2009

http://www.columbiaspectator.com/2009/10/18/cosmic-consciousness
\end{abstract}

\section{Conclusions: the universality of the universe}

In summary, based on a preliminary look, FETTU provides an opportunity to disseminate scientific information to the public in new and innovative ways. By selecting images that are aesthetically appealing and placing them in locations outside the traditional walls of science centers and planetariums, FETTU has exposed audiences to astronomy that otherwise may not have had or seized upon such an opportunity.

While the formal results of this project are still being formulated, there are several findings that have emerged from both preliminary evaluations and participant and local organizer feedback:

- Exposure to scientific content in these settings leads to inspiration and small learning gains. 
- Exhibits in these settings can potentially reach millions of people relatively inexpensively, especially considering the low cost and ability to duplicate the exhibits from a central repository of freely available material.

- $\quad$ FETTU exhibits provide opportunities to study how the public's voluntary engagement differs when the content is changed, such as art compared to science, as well as studying the effects of participant make-up and research into color appeal, color comprehension and other aestheticsrelated questions.

- Preliminary evaluation data suggest a stronger sense of engagement in groups (i.e., family units) vs. individuals.

- Utilizing simple educational activities along with providing human interaction appears to have the potential to increase the amount of engagement and effectiveness from these types of static displays.

- Different location types (outdoor vs. indoor, academic/institutional vs. unexpected, fast-paced vs. slow, etc.) can have an impact on visitor engagement.

- Such a project as FETTU can forge new partnerships between otherwise disparate organizations in the same geographic area and link groups across international boundaries.

"From Earth to the Universe" takes a grassroots-type of approach to bending the rules of more typical informal science learning environments. FETTU emphasizes the point that learning is everywhere and all around us with astronomy displays in unexpected locations. It separates popular astronomy images from perhaps their better known print versions or telepresense online, and presents them "bodily and in common". ${ }^{1}$ It utilizes the images' visual persuasion to spark socially-based engagement, enhancing the exploration of astronomical content through free-choice learning in a non-traditional environment.

The experiences of the organizers as well as the preliminary evaluation data suggest that this type of event has the potential to spark interest in astronomy, and hence, science and math topics. Much more research into these topics is, of course, required. However, FETTU has demonstrated that a provocative display of astronomical images can attract vast numbers of people, and provide a new opportunity to engage the public in scientific content. 


\section{Appendix 1a. Interview questions}

This questionnaire with content-specific and open-ended questions uses the standard method 7-item scale. The format of many of the survey items in this document was derived from NSF-funded informal education project evaluations done by Knight-Williams Research Communications.

\section{EARTH Ulniverse}

The following questions ask for your overall reactions to "From Earth to the Universe".

1. Overall, how do you feel about "From Earth to the Universe"? Circle one number on the scale of 1 to 7 for each pair of descriptions below. Please read the opposite descriptions carefully.

\begin{tabular}{|c|c|c|c|c|c|c|c|c|}
\hline Disliked overall & 1 & 2 & 3 & 4 & 5 & 6 & 7 & Liked overall \\
\hline Boring content & 1 & 2 & 3 & 4 & 5 & 6 & 7 & Interesting content \\
\hline Boring Storytelling & 1 & 2 & 3 & 4 & 5 & 6 & 7 & $\begin{array}{l}\text { Engaging } \\
\text { storytelling }\end{array}$ \\
\hline Visually dull & 1 & 2 & 3 & 4 & 5 & 6 & 7 & Visually exciting \\
\hline $\begin{array}{l}\text { Confusing } \\
\text { presentation }\end{array}$ & 1 & 2 & 3 & 4 & 5 & 6 & 7 & Clear presentation \\
\hline Learned nothing & 1 & 2 & 3 & 4 & 5 & 6 & 7 & $\begin{array}{l}\text { Learned } \\
\text { a lot }\end{array}$ \\
\hline $\begin{array}{l}\text { Decreased my } \\
\text { curiosity }\end{array}$ & 1 & 2 & 3 & 4 & 5 & 6 & 7 & $\begin{array}{l}\text { Increased my } \\
\text { curiosity }\end{array}$ \\
\hline $\begin{array}{l}\text { Would not } \\
\text { recommend }\end{array}$ & 1 & 2 & 3 & 4 & 5 & 6 & 7 & Would recommend \\
\hline
\end{tabular}

Please feel free to explain any of your ratings below:

2. Overall, how do you feel about the amount of information, science, and explanation of scientific principles in "From Earth to the Universe"? Circle one number on the scale of 1 to 7 (with 4 being "just right") for each pair of descriptions below. Please read the opposite descriptions carefully.

\begin{tabular}{|l|c|c|c|c|c|c|c|c|}
\hline $\begin{array}{l}\text { Too little } \\
\text { information }\end{array}$ & 1 & 2 & 3 & 4 & 5 & 6 & $\begin{array}{l}\text { Too much } \\
\text { information }\end{array}$ \\
\hline $\begin{array}{l}\text { Too little } \\
\text { science }\end{array}$ & 1 & 2 & 3 & 4 & 5 & 6 & 7 & $\begin{array}{l}\text { Too much } \\
\text { science }\end{array}$ \\
\hline $\begin{array}{l}\text { Not enough } \\
\text { explanation of } \\
\text { scientific } \\
\text { principles }\end{array}$ & 1 & 2 & 3 & 4 & 5 & 6 & $\begin{array}{l}\text { Too much } \\
\text { explanation of } \\
\text { scientific } \\
\text { principles }\end{array}$ \\
\hline
\end{tabular}

Please feel free to explain any of your ratings below: 
3. Did "From Earth to the Universe" cause you to think or feel about astronomy in a new or different way? Yes $\rightarrow$ Please explain how:

No $\rightarrow$ Please explain why not:

4. To what extent has seeing "From Earth to the Universe" increased or decreased your interest in learning more about each of the following? Please use the scale from 1 (decreased strongly) to 7 (increased strongly).

\begin{tabular}{|l|c|c|c|c|c|c|c|}
\hline $\begin{array}{l}\text { Has “From Earth to } \\
\text { the Universe" increased } \\
\text { or decreased your } \\
\text { interest in... }\end{array}$ & $\begin{array}{l}\text { Decreased } \\
\text { strongly }\end{array}$ & $\begin{array}{l}\text { Decreased } \\
\text { some }\end{array}$ & $\begin{array}{l}\text { Decreased a } \\
\text { little }\end{array}$ & $\begin{array}{l}\text { Neither } \\
\text { increased } \\
\text { nor } \\
\text { decreased }\end{array}$ & $\begin{array}{l}\text { Increased a } \\
\text { little }\end{array}$ & $\begin{array}{l}\text { Increased } \\
\text { some }\end{array}$ & $\begin{array}{l}\text { Increased } \\
\text { strongly }\end{array}$ \\
\hline Astronomy & 1 & 2 & 3 & 4 & 5 & 6 & 7 \\
\hline $\begin{array}{l}\text { The methods scientist } \\
\text { use to study astronomy }\end{array}$ & 1 & 2 & 3 & 4 & 5 & 6 & 7 \\
\hline Science in general & 1 & 2 & 3 & 4 & 5 & 6 & 7 \\
\hline Science-related careers & 1 & 2 & 3 & 4 & 5 & 6 & 7 \\
\hline
\end{tabular}

Please feel free to explain any of your ratings further:

5. Tell us something new you learned or discovered viewing "From Earth to the Universe":

http://www. fromearthtotheuniverse.org/ 


\section{Appendix 1b. Exhibit observation sheet}

This sheet template was employed to gather data about how visitors used the exhibit(s) via "tracking and timing" with an observation form and a watch with a timer/ second hand. All adherences to policies for informed consent for human subjects were made.

SAMPLE Exhibit OBSERVATION SHEET

$\begin{array}{lll}\text { Observer: } & \text { Date: Time of Day: } \\ \text { FETTU location: } & & \text { Total Visit Tim }\end{array}$

Composition of Visitor Group:

Key: $M=$ adult male $F=$ adult female

$\mathbf{G}=$ teen girl $\quad \mathbf{B}=$ teen boy $\mathbf{g}=$ girl $\mathbf{b}=$ boy

Cooperation in Groups yes no

Comment:
Behaviors observed

_look

_ read label

_talk

_show/explain to another

Images/ Exhibit Panels Visited (fill in):

Intro Panel / Time spent

Solar Sys / Time spent
Visitor comments overheard:

Notes: 


\section{Appendix 2}

Selected User Comments from U.S. Locations of Anchorage, Alaska; Memphis, Tennessee; Columbus, Ohio; and Chicago, Illinois demonstrating engagement (a) and small learning gains (b) from the openended question in Appendix 1a. "Tell us something new you learned or discovered viewing "From Earth to the Universe""':

(a)

- "Beautiful imagery; made me feel how insignificant wars and battles are."

- "I would like to know more about how you go about studying the universe."

- "This exhibit enhanced my appreciation of how tiny we are in the vastness around us..."

- "I had my two children "oohing" and "aahing" all through!"

- "I enjoyed seeing pictures from both amateur and professional astronomers and seeing old classic images in unique X-ray or infrared..."

- "Totally enjoyed it. [This is] not taught enough in school. Need more exposure for children."

- "Surprised to find them at O'Hare - great addition"

(b)

- "I learned the Universe is infinite!"

- "The picture of complete data that helped determine the age of the universe was new to me and very staggering and stunning."

- "I learned the world is infinite. We are trying to make sense of this infinite beauty."

- "[I learned] there are different types of telescopes"

- "[I learned] there are some things you can not see with only your eyes"

- "[I learned] Info about nebulae, Orion constellation, Milky Way \& other galaxies. The pictures are fantastic and fascinating... "

- "[I learned] the Milky Way will collide with Andromeda and not all galaxies are the same shape."

- "I learned what a Nebula actually is."

\section{Notes and references}

This material is based upon work supported by the National Aeronautics and Space Administration under proposal 08-EPO08-0068 issued through the Science Mission Directorate.

1 B.M. Stafford (1999), Artful Science: Enlightenment entertainment and the eclipse of visual education, Cambridge, Massachusetts, The MIT Press.

2 Full list of FETTU events: http://www.fromearthtotheuniverse.org/table_events.php.

3 http://www.astronomy2009.org/general/about/goals/.

4 P. Bell, B. Lewenstein, A.W. Shouse, M.A. Feder (eds) (2009), Learning science in informal environments: People, places and pursuits, Washington D.C., The National Academies Press.

5 L.F. Smith, J.K. Smith, K.K. Arcand, R.K. Smith and K. Keach (2009), Aesthetics and Astronomy: How experts and novices perceive astronomical images, submitted to Science Communication.

6 J.H. Falk (2005), Free-choice environmental learning: Framing the discussion, Environmental Education Research 11: 265-280.

7 J. Rounds (2004), Strategies for the curiosity-driven museum visitor, Curator 47: 389-412.

8 L.F. Smith and J.K. Smith (2006), The nature and growth of aesthetic fluency, in P. Locher, C. Martindale, L. Dorfman, V. Petrov and D. Leontiev (eds.), New directions in aesthetics, creativity, and the psychology of art, pg. 47-58, Amityville, NY: Baywood.

9 J.K. Smith (2008), Learning in informal settings. Psychology of Classroom Learning: An Encyclopedia, Farmington Hills, MI, Cengage Learning.

10 G.C. Cupchik, L. Shereck and S. Spiegel (1994), The effects of textual information on artistic communication, Visual Arts Research 20: 62-78; J.K. Smith and L.F. Smith (2001), Spending time on art, Empirical Studies in the Arts 19: 229-236. 
11 J. Lave and E. Wenger (1993), Situated learning: Legitimate peripheral participation, New York, Cambridge University Press.

\section{Authors}

Kimberly Kowal Arcand is the visualization and media production coordinator for NASA's Chandra Xray Observatory and is based at the Chandra X-ray Center at the Harvard-Smithsonian Center for Astrophysics in Cambridge, Mass., USA. She has been an employee of the Smithsonian Institution since 1998. She is co-chair for the international "From Earth to the Universe" exhibit task group and principal in the international "Aesthetics \& Astronomy" project. Contact: 60 Garden Street, MS 70, Cambridge, MA 02138 USA, 617.218.7196. E-mail:kkowal@cfa.harvard.edu.

Megan Watzke is the press officer for NASA's Chandra X-ray Observatory and is based at the Chandra X-ray Center at the Harvard-Smithsonian Center for Astrophysics in Cambridge, Mass., USA. She is cochair for the international "From Earth to the Universe" exhibit task group. Contact: 60 Garden Street, MS 70, Cambridge, MA 02138 USA; 617.496.7998. E-mail: mwatzke@cfa.harvard.edu.

How tO CITE: $\quad$ K. Arcand and M. Watzke, Bringing the universe to the street. A preliminary look at informal learning implications for a large-scale non-traditional science outreach project, Jcom 09(02) (2010) A01. 